\title{
A Study on Financial Literacy and Need for Financial Education
}

\author{
${ }^{1}$ Maria Emma and ${ }^{2}$ Sofia Anya \\ ${ }^{1}$ Bauman Moscow State Technical University, Russia, 105005 \\ 1emmamaria01@hotmail.com
}

\author{
Article Info \\ Journal of Journal of Enterprise and Business Intelligence (http://anapub.co.ke/journals/jebi/jebi.html) \\ Doi: https://doi.org/10.53759/5181/JEBI202101015 \\ Received 25 January 2021; Revised form 18 March 2021; Accepted 08 April 2021. \\ Available online 05 July 2021. \\ (C2021 Published by AnaPub Publications.
}

\begin{abstract}
Fillecya (Financial Literacy) Boards adopts the idea of financial literacy education for the community, where the need for people to have better knowledge, confidence, and skills in financial management, where experts believe that financial literacy knowledge is significantly related to individual financial behavior of consumers. The important point in this research is how to teach financial literacy early on to children as the pillars of national development. One reliable alternative strategy in teaching children is through games, where children learn while playing and education will enter naturally. This research emphasizes the Fillecya Board as a medium for early financial literacy education. Scientifically, the Fillecya Board will have a positive contribution to scientific development in the field of financial literacy which is in line with the times. On the other hand, Fillecya also acts as a place for learning while playing for children and a means to train decision making. From the social aspect, fillecya will be able to increase solidarity between children and train healthy competition. By using the Research and Development research approach by using the Four-D model, namely define, design, develop and disseminate. For the first year, the results of this study show that all teachers which is this research respondent felt the need to develop financial literacy learning media. This is considered necessary because so far, the direct instruction method has not been able to make students understand about the material and need more time to achieve this learning goal. The results of this study indicate that more interactive media are needed in this study, one of which is fillecya.
\end{abstract}

Keywords - Fillecya, Financial Literacy, Games, Learning Media, Children,

\section{INTRODUCTION}

The increasingly sophisticated technological developments in the disruptive era had an impact on the development of the global economy. The global economic development itself will have an impact on the public's financial system, [1] the number of financial service products issued by financial institutions for convenience in economic activities. However, if this is not accompanied by public knowledge about finance or a low level of financial literacy, it will harm the economic condition of the community itself, such as financial problems. The community's inability to manage finances properly will result in various financial problems. It is so important for someone to have a good understanding of finances because it will influence financial decisions. One of the basic factors in making financial decisions is financial knowledge. Financial knowledge is all the knowledge and understanding of a person regarding the world of finance which is the basis for making financial decisions.

Based on a survey conducted by OJK in 2016 covering 34 provinces with 67 cities/regencies taking into account gender and strata of urban/rural areas with a calculation of the level of financial literacy which consists of parameters of knowledge, skills, beliefs, attitudes, and behavior of the public regarding finance. OJK said that financial literacy in Indonesia from 2013 to 2016 has increased. The Indonesian Public Financial Literacy Index in 2013 increased by 7.9\%, from $21.8 \%$ to $29.7 \%$ in 2016 [2]. When viewed from the provincial level, West Sumatra Province is still below other provinces in the level of financial literacy.

Based on Figure 1, it shows that the level of financial literacy in West Sumatra Province is still below the national average. In fact, West Sumatra Province is even below the Provinces of South Sumatra, Bangka Belitung, Riau, East Nusa Tenggara and Bengkulu. The low level of financial literacy can be overcome with financial education. Financial education is a process that inspires individuals to have financial plans in the future to obtain prosperity following the lifestyle and patterns that the individual lives. Financial education should be given from an early age to students. Providing knowledge about finance from the start will affect the way students manage finances, so students will be familiar and more competent in managing their finances [3]. Furthermore, a lack of financial literacy can be seen as the root cause of many problems facing individuals and families especially in poor and rural areas, including the proliferation of subprime mortgage loans and payroll loans [4]. Furthermore, the more involved children are in saving and recognizing money, the more they will increase their financial literacy. 


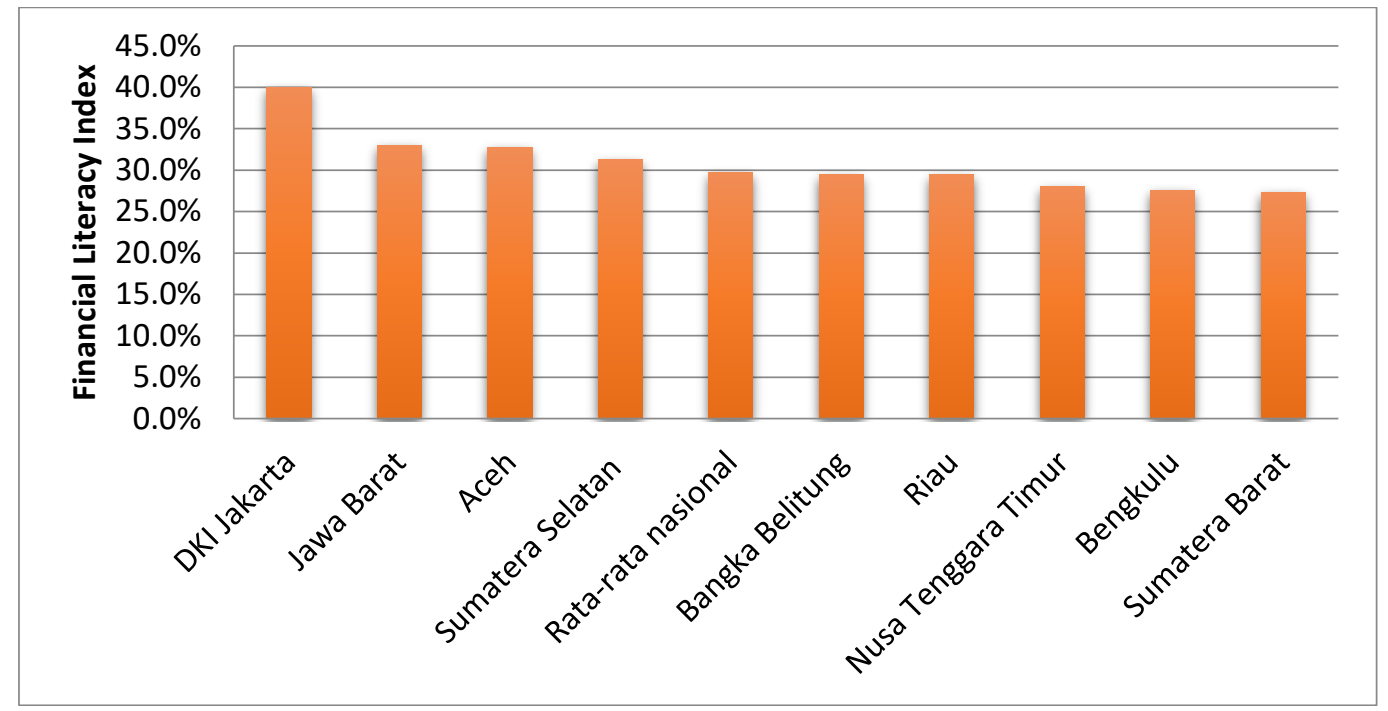

Fig 1. The level of financial literacy of Indonesian society in 2016 by province

Source: National survey results, financial literacy, and inclusion of OJK 2017 (data processed by the author, 2019)

In [5] Dane revealed that many parents do not have the skills to teach financial literacy education to their children. Furthermore, many parents think that financial literacy education should only be given to children at the age of 18 . Danes further in the results of his study found that parents are the main agents in the socialization of financial knowledge, but in fact, the majority of parents do not provide financial literacy education that is appropriate for the purpose [6]. Children learn about finance through instruction, participation and practice (explicitly) and through observation (implicitly) [7], [19]. There are still many public opinions that learning about literacy is the responsibility of educational institutions. For this reason, schools or teachers must be able to be creative in introducing financial literacy early to students but still in the context of adjusting the character of the students themselves. Materials related to financial literacy have started to be taught since basic education, but in reality, the level of public financial literacy in West Sumatra is still below the national average. One of the triggers for this problem is thought to be inaccurate in the learning media and strategies used by teachers in introducing financial literacy to children. The right learning media will make students understand the material faster, learning objectives can be achieved and the skills for direct application in the field. There are two important elements in the teaching and learning process, namely teaching methods and learning media. These components mutually influence the success of students in learning expressed by the achievement of the learning objectives. Learning media is anything that can be used or utilized to transmit messages (learning materials) so that it can stimulate the attention, thoughts, interests, and feelings of students in the learning process to achieve learning goals.

One of the media that can be used in the learning process in improving student financial literacy is the Media Fillecya (Financial Literacy) Board. Fillecya Board is a learning medium designed to improve financial literacy in society in general and students in particular. Fillecya Board is a media in the form of a game board designed as an implication of financial literacy education for children [2]. The existence of learning media in the form of games will stimulate the potential and understanding of students [8]. In previous research, it was found that teachers stated the need for the development of financial literacy learning media in early education [9]. This research discuss about what is students think about fillecya (financial literacy) board as a media in understanding financial early?

\section{METHODS}

This research was conducted using research and development methods to see how capable the fill is to be a medium for financial literacy education for children, and also to produce new knowledge [10]. The development model used in this study is the Four-D development model, according to, there are 4 stages or steps in developing this model, namely define, design, develop and disseminate. This research is the initial stage of this model, the define stage. In this initial stage, the researcher will conduct a needs analysis to analyze the fundamental problems faced in learning financial literacy. Furthermore, an analysis of the students' needs in using media in learning financial literacy was carried out. This study had 52 respondents, where the subjects of the respondents were grade 4 students of SD Negeri 38 Lubuk Buaya, Padang city who had taught money and savings (financial literacy). The gender of the respondents here consisted of 26 male students and 26 female students. Data were collected using an open questionnaire and followed by interviews. The data 
is processed qualitatively by testing the validity of the data through data triangulation. In fulfilling the validity of the data this research was conducted triangulation with sources. According to Patton, triangulation with sources means comparing and re-examining the level of trust in information obtained through different time and tools in qualitative research. Triangulation with sources conducted in this study is to compare the results of interviews with the contents of related documents.

\section{RESULTS AND DISCUSSION}

Of the existing respondents, the average age is 8-9 years. Children aged 8-9 years are a period of child development at the imitation stage, where at that time children imitate a lot from the surrounding environment, for example from the family environment, peers, and the community, both in the child's home and school environment. In the first item in the questionnaire, it can be seen whether the students have learned about money and savings material. From the results of research in the field that students have studied material about money and savings, it is evident from the results of the diagram that $90 \%$ of students answered yes and $10 \%$ answered no. So it can be concluded that students have learned material about material money and savings. In the next question, students were asked about the students' ability to understand the material about money and savings. It can be seen from the diagram above, as many as $83 \%$ answered yes and $17 \%$ answered no. From this percentage above, we can conclude that students already understand the material about money and savings. The next question the students were asked about the student's level of preference regarding currency and savings. Of the respondents, $96 \%$ answered yes and $4 \%$ answered no. In other words, it can be concluded that students are happy with the material about money and savings. It also has an impact on the interest of students studying material about money and savings, as shown in figure 2 .

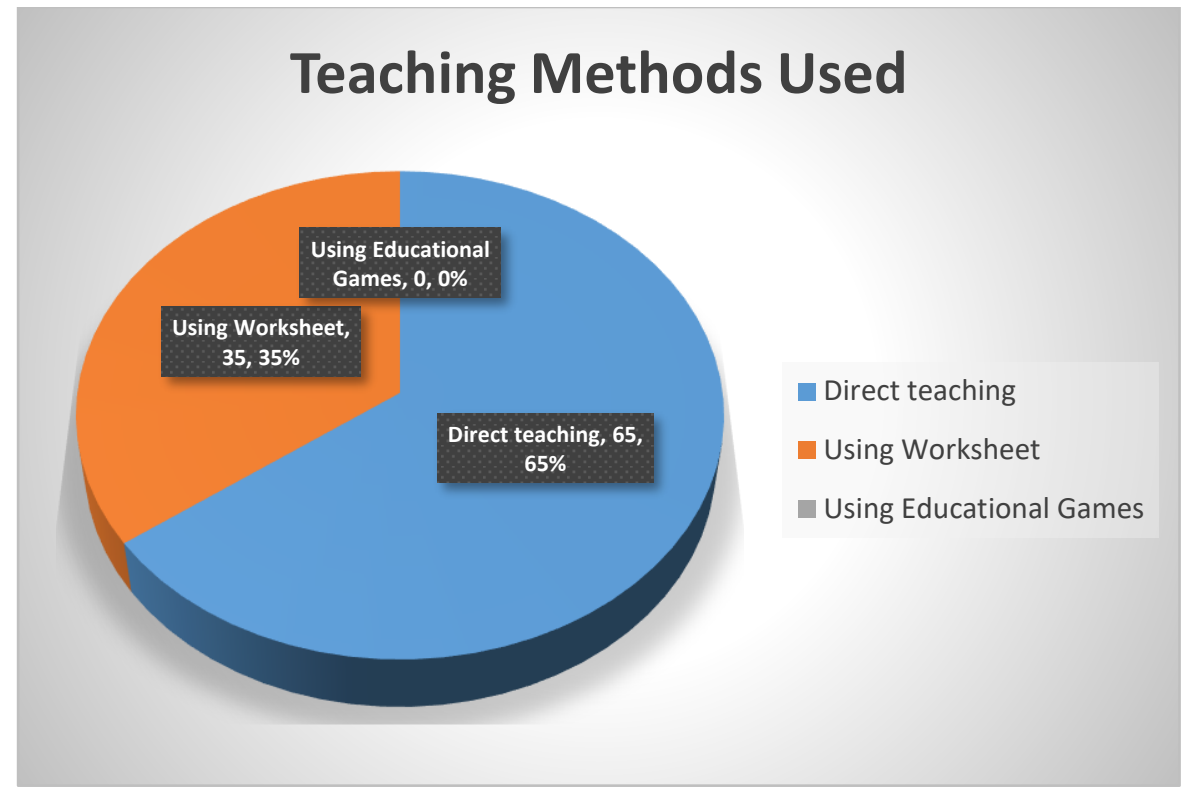

Fig 2. The teaching methods used by the sample teachers (2019)

In the next question, the students asked about how the teacher delivered material about money and savings. Of the 52 students, $65 \%$ answered how to teach material about money was using the lecture method (explaining), and as many as $35 \%$ of students answered using worksheets and none of them answered that the teacher used the game method in teaching material about money and savings. From the diagram above, we can conclude that the use of the lecture method is still predominantly carried out by teachers. It is inversely proportional to the wishes of students. Where students want to learn methods with game methods. We can see from the diagram that shows the game learning method is preferred over the method of teaching lectures or explaining. 


\section{THE STUDENT'S PREFERRED WAY OF LEARNING}

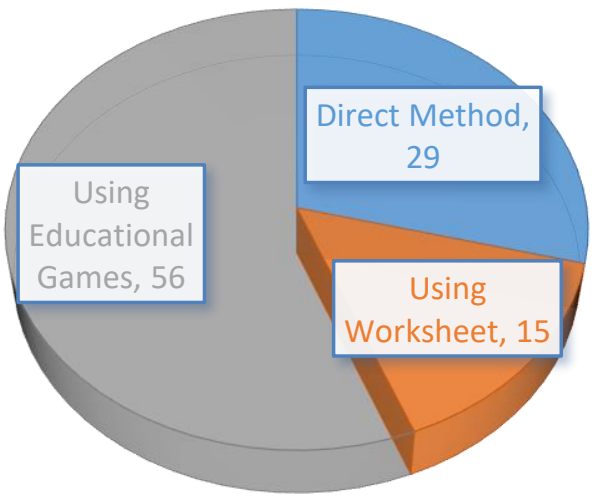

Fig 3. The student's preferred way of learning (2019)

From the figure 3, 52 respondents can describe as many as 56\% want the teacher to use the learning method while playing, as many as $29 \%$ want the teacher to continue using the lecture method (explaining) and the other using the LKS. And here the researcher also asked the number of allowance students often brought. The average student allowance per day is IDR 5,000 - 10,000. As many as 58\% have an allowance of IDR 5,000-10,000, - per day, and 9\% have an allowance of IDR 1,000 - 5,000 and also as much as 33\% over IDR 10,000. The next question is to test the student's ability to use the money that has been given by the parents. From the answers of the most dominant respondents answered by students is to buy food with a percentage of $48 \%$ of a total of 52 respondents. And the least is the complex demand of $2 \%$ of the total respondents. This shows that students still think that if they are given money by their parents, they will buy it into food, or the consumerism of the child or student is high as shown in figure 4.

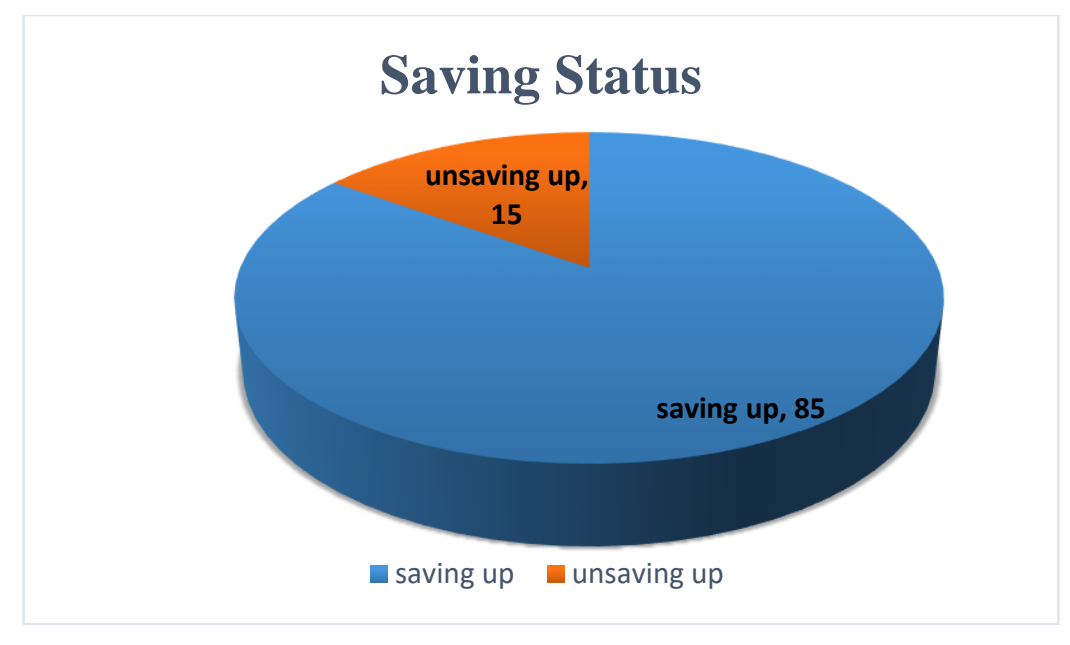

Fig 4. Saving status of students

In the next question, the researcher asked about students had savings or not. From the results, the respondents answered that $85 \%$ said they had savings and $15 \%$ did not have savings. This shows that students have knowledge of savings or investments in the future. 


\section{Saving Purpose}

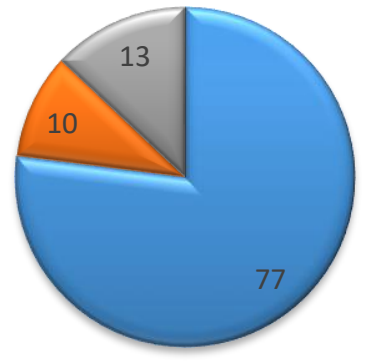

घConsumtive $\square$ Future Purpose $\square$ Has No saving

Fig 5. Saving purpose of the students

Continuing the question of saving ownership with an analysis of the purpose of saving of all then, the purpose of ownership of student savings was $77 \%$ using savings for consumptive purposes. And only $10 \%$ of students use their savings for the future. Only for consumptive needs. The next question was asked about how the student-managed the finances he had. From the diagram above, the knowledge to budget is quite low. It can be seen that $72 \%$ of respondents do not understand how to properly manage their money and savings as shown in figure 5 .

From the data obtained in this study, there are several unique findings, namely: First, so far, the learning of financial literacy has only focused on the introduction of savings only and has been explained more by using lectures and worksheets methods. Each learning method has advantages and disadvantages. The lecture method gives the teacher freedom in mastering the class and organizing the class. Besides that, the lecture method also allows the teacher to control classroom conditions better, and this method also does not require diverse classroom settings and complicated preparation. On the other hand, the weaknesses of this method are

1) The material mastered by students is limited to what the teacher provides,

2) Can cause verbalism to students,

3) Can cause boredom in students in learning,

4) It is difficult to determine whether students have understood the material or not yet, and

5) The nuances of learning become passive.

This applies the same as using worksheets in learning.

LKS or Student Worksheets are learning tools that teachers can use in increasing student involvement or activities in the teaching and learning process. In general, student's worksheets contain practical instructions, experiments that can be done at home, material for discussion, crossword puzzles, portfolio assignments, and practice questions, as well as all forms of instructions that can encourage students to take part in the learning process.

Another opinion was expressed which states worksheets as a type of hand out that are intended to help students learn in a guided manner (guided discovery activities). This means that through student worksheets, students can perform activities and at the same time obtain a kind of summary of the material on which the activity is based. However, the weakness of this LKS is that there is no guarantee of the quality of the worksheets used, besides so far, the LKS circulating in the market place more emphasis on practicality and have not emphasized the student work process. Second, students like the learning provided by the teacher. However, students prefer it if the learning methods and media are more concrete and learning is carried out actively and fun. Psychologically elementary school children are still at the concrete operational stage which has the character of being happy to play, move, work in groups, and enjoy feeling or doing it directly. This indicates that Paikem's learning will be more in line with their development.

Third, Fillecya is the answer to making learning fun and more meaningful in making student financial decisions. In other words, students prefer active, innovative, creative, and fun learning. Learning in this context is interpreted as an active process in building knowledge and or constructing meaning.

In the process, a student who is learning will be involved in a social process. The process of constructing meaning continuously based on the view of constructivism. This view explains how students build understanding and knowledge about objects around them through direct experience. Fillecya answers this challenge. Because the fillecya is concrete 
media in learning financial literacy where students play roles. Students play an active role and are illustrated as having full authority in making their financial decisions. Students also interact with each other. More importantly, students are introduced to financial literacy products.

Fourth, students are more likely to be consumptive in spending their money and have not been able to make a simple financial budget. The knowledge that is not so well-honed has an impact on irrational consumption patterns. Early financial literacy education will provide a strong foundation for children to be more skilled in financial decision making . Furthermore, this media will also help students who do not understand how to make a spending budget more understandable and naturalized in making financial decisions in the future.

\section{CONCLUSIONS}

The findings of this study indicate that so far financial literacy learning has been carried out using the lecture method using blackboard media and partly also using worksheets. The weakness that was found was that students only understood savings as a product of financial literacy and it was limited to knowledge. Students also hope that future financial literacy learning can take the form of fun learning using a game approach. The 52 samples studied, $72 \%$ of students did not understand the concept of simple budgets and the tendency to use money consumptively. To minimize the risk of sustainable irrationality, a financial literacy education medium that is friendly to early childhood development is needed. Fillecya Board is a media in the form of board games designed as an implication of financial literacy education for children. With the fillecya, students are guided to understand financial literacy products and simple financial decision making. The use of this game media will make learning more meaningful and fun. Furthermore, this media might be developed in the form of digital files, given the learning conditions that do not allow face-to-face learning.

\section{References}

[1]. W. G. Shenkir, T. L. Barton, and P. L. Walker, “Enterprise Risk Management: Lessons from the Field," Enterprise Risk Management, pp. 441-463, Dec. 2011.

[2]. J. R. S. Fraser and B. J. Simkins, "Enterprise Risk Management: An Introduction and Overview," Enterprise Risk Management, pp. 1-17, Dec. 2011.

[3]. A. Rom and C. Rohde, "Enterprise resource planning systems, strategic enterprise management systems and management accounting," Journal of Enterprise Information Management, vol. 19, no. 1, pp. 50-66, Jan. 2006.

[4]. S. Chaki, "Components of Enterprise Information Management," Enterprise Information Management in Practice, pp. 15-24, 2015.

[5]. Y. G. Chen, "B2B, B2C and Virtual Enterprise Management Systems," Journal of Enterprise Business Management, pp. 118-127, Dec. 2020.

[6]. G. Niehaus, "The Role of Insurance in Enterprise Risk Management,” Enterprise Risk Management, pp. 161-173, 2016.

[7]. S. Tonchia, "Knowledge Management in Enterprise Networks," Process Management for the Extended Enterprise, pp. 47-67, 2004.

[8]. S. Goodyear, "Overview of Enterprise Content Management," Practical SharePoint 2013 Enterprise Content Management, pp. 3-22, 2013.

[9]. A. Simon, "The Rebirth of Enterprise Data Management," Enterprise Business Intelligence and Data Management, pp. 1-15, 2014.

[10]. Q. Liao and T. Li, "Effective network management via dynamic network anomaly visualization," International Journal of Network Management, vol. 26, no. 6, pp. 461-491, Jul. 2016. 